\title{
Robust fault detection in open loop vs. closed loop
}

\author{
Niemann, Hans Henrik; Stoustrup, J.
}

Published in:

Proceedings of 36th IEEE Conference on Decision and Control

Link to article, DOI:

10.1109/CDC.1997.649678

Publication date:

1997

Document Version

Publisher's PDF, also known as Version of record

Link back to DTU Orbit

\section{Citation (APA):}

Niemann, H. H., \& Stoustrup, J. (1997). Robust fault detection in open loop vs. closed loop. In Proceedings of 36th IEEE Conference on Decision and Control (Vol. 5, pp. 4496 - 4497). IEEE.

https://doi.org/10.1109/CDC.1997.649678

\section{General rights}

Copyright and moral rights for the publications made accessible in the public portal are retained by the authors and/or other copyright owners and it is a condition of accessing publications that users recognise and abide by the legal requirements associated with these rights.

- Users may download and print one copy of any publication from the public portal for the purpose of private study or research.

- You may not further distribute the material or use it for any profit-making activity or commercial gain

- You may freely distribute the URL identifying the publication in the public portal

If you believe that this document breaches copyright please contact us providing details, and we will remove access to the work immediately and investigate your claim. 


\section{Robust Fault Detection in Open Loop vs. Closed Loop}

\author{
H.H. Niemann*
}

\begin{abstract}
The robustness aspects of fault detection and isolation (FDI) for uncertain systems will be considered in this paper. The FDI problem will be considered here in a standard problem formulation. The FDI design problem will be analyzed both in the case where the control input signal is considered as a known external input signal (open loop) and when the input signal is generated by a feedback controller.
\end{abstract}

\section{Introduction}

In [2], the combined setup for both feedback and fault detection filter design problem has been considered, where a complete analysis of the combined feedback controller/fault detection filter has been given for both nominal systems as well as for uncertain systems. The results of this analysis is that there is a separation between the design of the feedback controller and the fault detection filter in the nominal case which does not exist in the uncertain case. The reason for this missing separation in the uncertain case is that there is a trade-off between performance in the feedback loop and performance for the fault detection filter.

Another approach in fault detection is to consider only the system without taking into account how the control signal is calculated.

This setup has been considered in several papers, see e.g. [1] and the references therein.

The mäin issue in this paper is to give an analysis of the FDI design problem both in the case when the relation between $u$ and $y$ is known and when it is not known. Nominal systems as well as uncertain systems will be considered.

*Department of Automation, Technical University of Denmark, Building 326, DK-2800 Lyngby, Denmark. E-mail: hhnoiau.dtu.dk

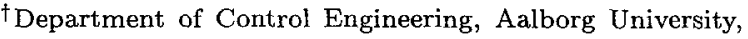
Fredrik Bajersvej 7C, DK-9220 Aalborg, Denmark. E-mail: jakob@control.auc.dk, $\mathrm{W}^{3}$ : http://www.control.auc.dk/ jakob .
J. Stoustrup ${ }^{\dagger}$

\section{Problem Formulation}

Consider the setup given in Figure 1.

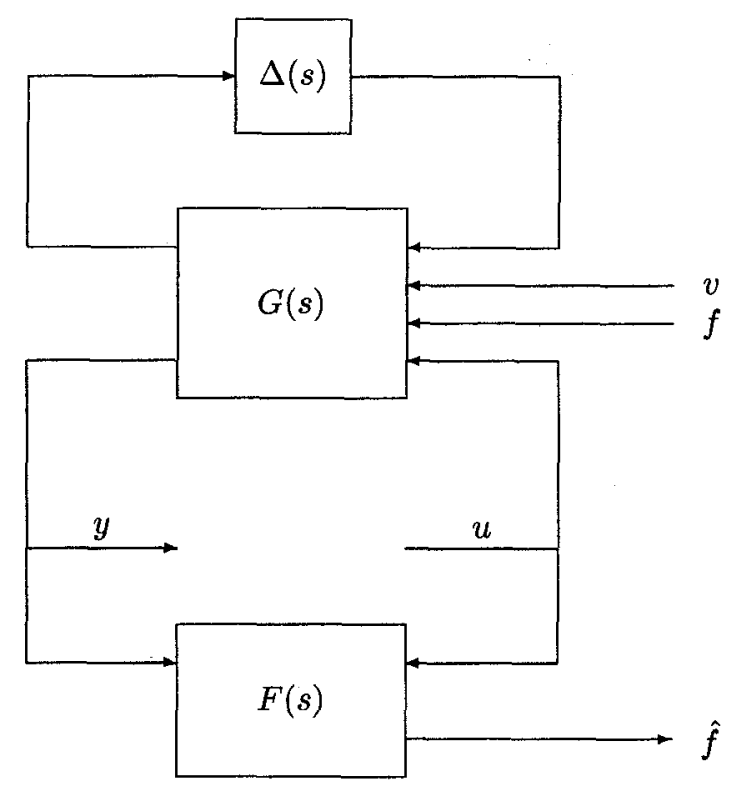

Figure 1: General setup for robust fault detection in open loop.

The system $G$ in Figure 1 has the following form:

$$
\left[\begin{array}{c}
z \\
y
\end{array}\right]=\left(\begin{array}{cccc}
G_{z w} & G_{z v} & G_{z f} & G_{z u} \\
G_{y w} & G_{y v} & G_{y f} & G_{y u}
\end{array}\right)\left(\begin{array}{c}
w \\
v \\
f \\
u
\end{array}\right)
$$

where $z$ and $y$ are the external output signal and the measurement output signal respectively. The inputs are: external input $w$ from the uncertain block $\Delta$, disturbance input $v$, fault input signal $f$ and the control input signal $u$, respectively. It will further be assumed that the perturbation block $\Delta$ is scaled such that $\|\Delta(i \omega)\| \leq 1, \forall \omega$ and the scaling function is included in $G$. There is no assumption about the structure of $\Delta$. Further, it is also assumed that all other relevant weight matrices are included in $G$. 
The design problem is to design a FDI filter $F(s)$ following form:

such that the estimation error $e$ defined by

$$
\begin{aligned}
e & =f-\hat{f} \\
& =f-\left(F(s) y-F(s) G_{y u} u\right)
\end{aligned}
$$

is minimized in some sense.

\section{Nominal FDI Analysis}

In this case, the system in (1) takes the following form:

$$
y=\left(\begin{array}{lll}
G_{y v} & G_{y f} & G_{y u}
\end{array}\right)\left(\begin{array}{c}
v \\
f \\
u
\end{array}\right)
$$

The estimation error is then given by:

$$
e_{\text {open }}=\left(I-F G_{y f}\right) f-F G_{y v} v
$$

It is apparent from (4) that it is not possible to make estimation of $f$ if the disturbance $v$ is in the same frequency range as the fault signal $f$ is and has the same direction at the system. Hence, there is a trade-off between fault detection and disturbance attenuation.

In the closed loop case, the control input signal $u$ is given by

$$
u=K(s) y
$$

where $K(s)$ is a stabilizing feedback controller. The closed-loop system from (3) with (5) is then given by:

$$
y=\left[\begin{array}{ll}
S G_{y v} & S G_{y f}
\end{array}\right]\left[\begin{array}{l}
v \\
f
\end{array}\right]
$$

where $S=\left(I-G_{y u} K\right)^{-1}$ is an output sensitivity function. The fault estimation error $e$ for the nominal closed-loop system is given by:

$$
e_{\text {closed }}=\left(I-F S G_{y f}\right) f-F S G_{y v} v
$$

The only difference between the estimation error for the open loop in (4) and for the closed loop in (7), is that the sensitivity function $S$ is included in (7). So, if the filter in (7) is selected as $F_{\text {closed }}=$ $F_{\text {open }} S^{-1}$, we get exactly the same equation for the estimation error as in the open loop case. The open loop and the closed loop cases are equivalent in the nominal case.

\section{Uncertain FDI Analysis}

When the loop from $z$ to $w$ is closed by the uncertain block $\Delta, w=\Delta z$, the system in (1) takes the

$$
y=\left(\begin{array}{lll}
\bar{G}_{y v} & \bar{G}_{y f} & \bar{G}_{y u}
\end{array}\right)\left(\begin{array}{c}
v \\
f \\
u
\end{array}\right)
$$

where the matrices are: $\bar{G}_{y v}=G_{y w} \Delta S_{\Delta} G_{y v}+G_{y v}$, $\bar{G}_{y f}=G_{y w} \Delta S_{\Delta} G_{y f}+G_{y f}, \bar{G}_{y u}=G_{y w} \Delta S_{\Delta} G_{y u}+$ $G_{y u}$, and $S_{\Delta}=\left(I-G_{z w} \Delta\right)^{-1}$.

The estimation error is then given by:

$$
\begin{aligned}
e_{\text {open }}= & \left(I-F \bar{G}_{y f}\right) f-F \bar{G}_{y v} v \\
& -F G_{y w} \Delta S_{\Delta} G_{y u} u
\end{aligned}
$$

With the perturbation block present in the system, three additional terms appear in the equation for the estimation error, (9), compared to the nominal case.

As in Section 3, the control input signal $u$ is based on a feedback controller $K(s)$. Closing the loop in (8) with a feedback controller $K(s)$, we get the following system (with $\bar{G}_{y v}, \bar{G}_{y f}$, and $\bar{G}_{y u}$ as defined in (8)):

$y=\left[\begin{array}{ll}\left(I-\bar{G}_{y u} K\right)^{-1} \bar{G}_{y v} & \left(I-\bar{G}_{y u} K\right)^{-1} \bar{G}_{y f}\end{array}\right]\left[\begin{array}{l}v \\ f\end{array}\right]$

The fault estimation error in the closed loop for uncertain systems is then given by:

$$
e_{\text {closed }}=\left(I-F S \bar{G}_{y f}\right) f-F S \bar{G}_{y v} v
$$

where $S=\left(I-\bar{G}_{y u} K\right)^{-1}$.

The above equation for the fault detection error signal depends on the uncertainty in a rather complicated way in the general case. However, it can easily be seen that there will be a trade-off between FDI and control performance in nonpathological cases.

\section{Conclusion}

Fault detection in open loop vs. closed loop has been considered in this paper for both nominal systems as well as for uncertain systems. In the nominal case, there is in principle no difference between open loop and closed loop fault detection. This is not the case for uncertain systems. In this case, there is a trade off between good fault detection and good performance of the closed loop system.

\section{References}

[1] P.M. Frank. Analytical and qualitative modelbased fault diagnosis - A survey and some new results. European Journal of Control, 2:6-28, 1996.

[2] J. Stoustrup, M.J. Grimble, and H.H. Niemann. Design og integrated systems for the control and detection of actuator/sensor faults. Sensor $R e$ view, 17:138-149, 1997. 